\title{
Immunohistochemical Localization of Vascular Endothelial Growth Factor in Esophageal Cancer
}

\author{
YUTAKA OGATA, YOSHIKAZU HARADA, TERUHIKO FUJI, HIDEAKI YAMANA, \\ HIROMASA FUJITA AND KAZUO SHIROUZU \\ Department of Surgery, Kurume University School of Medicine, \\ Kurume 830, Japan
}

Received for publication March 14, 1996

\begin{abstract}
Summary: We have studied the expression of vascular endothelial growth factor (VEGF) in esophageal cancer using immunohistochemistry. A total of 101 specimens of esophageal cancer tissue were fixed by formalin, embedded in paraffin wax, and examined in $3 \mu \mathrm{m}$ sections by avidin-biotin peroxidase complex method. VEGF was noted in the cytoplasm of normal esophageal glandular cells, monocyte-macrophages, squamous carcinoma cells and of the vascular endothelial cells themselves. VEGF expression by monocyte-macrophages was observed in all cases, in contrast the incidence of VEGF expression in the tumor cells was relatively low at $26.7 \%$ of all specimens. However, in the cases where the tumor cells were positive for VEGF, it was discovered that the main source of the VEGF production was the tumor cells themselves. In the cases with proper mucosal invasion the incidence of VEGF expression by the tumor cells was quite low at $7.6 \%$. However, when the tumor invaded the submucosal layer the expression increased to $33.3 \%$. There was also a significant correlation in those with the submucosal invasion between the expression of VEGF in the tumor cells and the density of microvessels at the tumor invasive edge. These results suggest that VEGF may play an important role in tumor progression and in the angiogenesis via auto-crine and para-crine mechanisms in esophageal cancer.
\end{abstract}

Key words: vascular endothelial growth factor (VEGF) - immunohistochemistry - esophageal cancer - histopathological factors - vessel count at tumor invasive edge - angiogenesis

\section{Introduction}

Previous experimental studies (Liotta et al. 1974; Folkman, 1986) have demonstrated that tumor growth and metastasis are dependent upon angiogenesis. Increased vascularity may allow not only for an increase in tumor growth but also for hematogenous tumor embolization. Weidner et al. (1991) reported a statistically significant correlation between the incidence of metastasis and the density of microvessels in invasive breast cancer. This finding has been confirmed in

Reprint requests to: Yutaka Ogata, M.D., Department of Surgery, Kurume University School of Medicine, 67 Asahi-machi, Kurume 830, Japan. 
numerous studies of breast cancer (Bosari et al. 1992; Guidi et al. 1994) as well as cervical cancer (Smith-McCune and Weidner, 1994), and other tumors (Weidner et al. 1993).

VEGF are known to induce angiogenesis in rodent tumor models (Leung et al. 1989; Ferrara et al. 1992). It is also well known that VEGF has a specific potential for proliferating endothelial cells (Keck et al. 1989; Leung et al. 1989; Conn et al. 1990). Further identification of the specific angiogenic factor may provide a target for anti-angiogenic therapy in the neoplasm.

In this study, we report the localization of VEGF and a correlation between the expression of VEGF in tumor cells and the density of vessels in esophageal cancer.

\section{Materials and Methods}

\section{Patients}

Formalin-fixed and paraffin-embedded specimens of esophageal cancer were studied from 101 ramdomly chosen patients who had undergone surgery in the 1st Department of Surgery, Kurume University School of Medicine between 1989 and 1994. The cancer specimens involved of 13 either in situ (ep) or invading the muscularis mucosa ( $\mathrm{mm}$ ), 24 invading the submucosa (sm), 15 pT2, 31 pT3 cancers, and 18 pT4 (according to TMN classification). After an initial review of all available hematoxylin and eosinstained (H.E.) slides of the surgical specimens, we selected one paraffin block in which the tumor invasive edge and the viable tumor were shown from each case for study. Consecutive $3 \mu \mathrm{m}$ sections were recut from each block. One section from each case was stained by H.E., a second was stained by elastica-vanginson stain (EVG), and a third was immunostained for VEGF.

\section{Immunohistochemical staining}

Immunohistochemical staining was performed by avidin-biotin peroxidase complex method. Anti-human VEGF mouse monoclonal IgG (R\&D SYSTEM, Minneapolis) was used at 1:200 dilution as a primary antibody. Negative controls used all reagents except the primary antibody.

Evaluation of immunostaining of VEGF and vessel counting

We have evaluated positive staining of cell types for VEGF. The intensity of staining for VEGF in tumor cells was graded on a scale of 0 (representing no detectable stain or only a few positive cells), $1+$ (representing a cluster of positive cells, but less than 50\%), and $2+$ (representing more than $50 \%$ positive). In 24 cases of sm invasion, vessel counts were made at the invasive edge by light microscopy after EVG staining.

\section{Statistical analysis}

Correlation between the vessel counts and the intensity of VEGF was investigated by standard chi-square test. The pvalue level of significance was set at 0.05 .

\section{Results}

Localization of VEGF in esophageal cancer tissue

VEGF staining was noted in the cytoplasm of normal esophageal glandular 

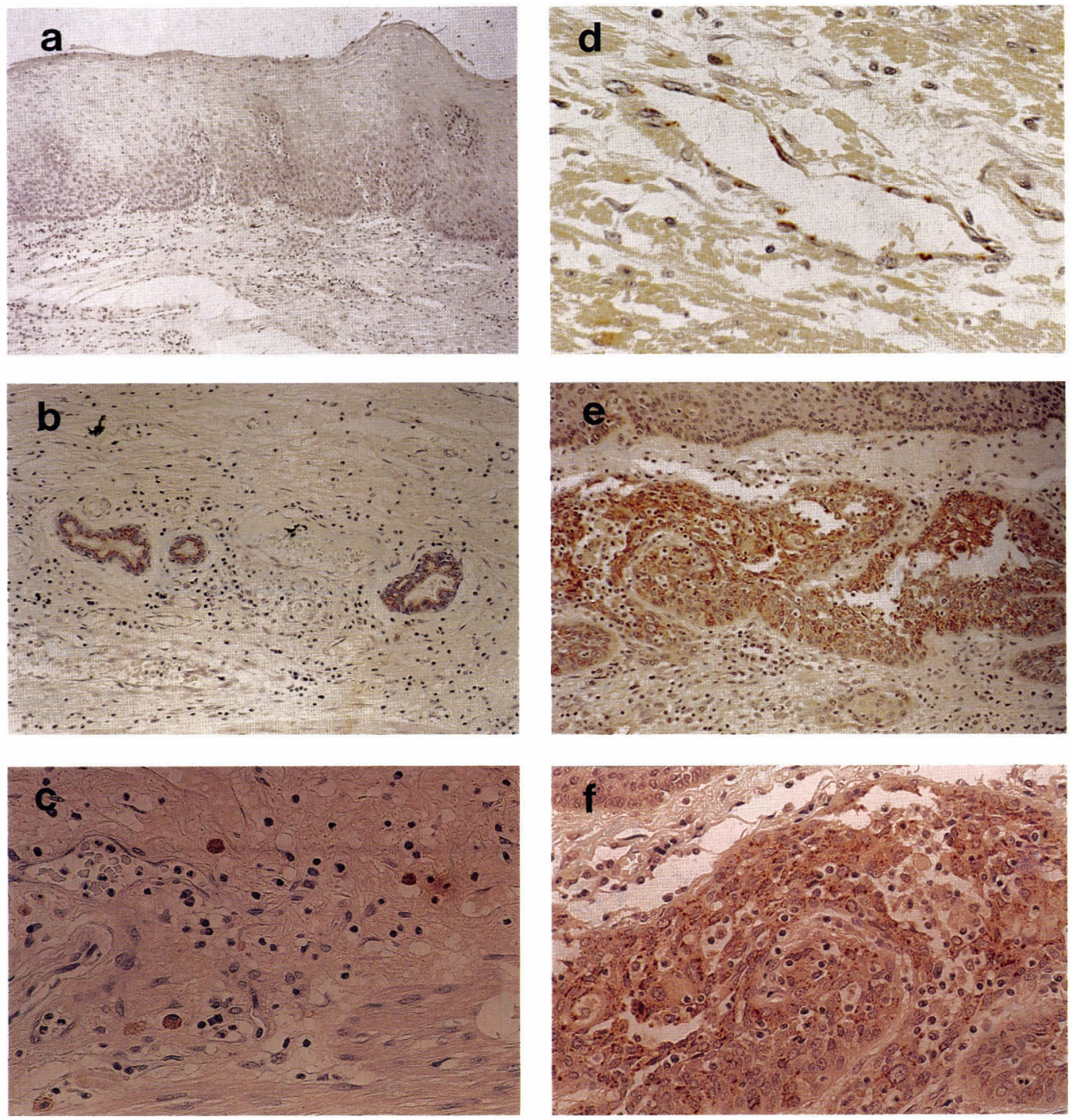

Fig. 1. Immunohistochemical staining for VEGF in esophageal cancer tissue.

Normal squamous epithelial cells are negative for VEGF (a: $\times 50)$; Supra nuclear staining of VEGF is seen in esophageal glandular cells adjacent the tumor (b: $\times 100)$; Minute granular or difuse cytoplasmic staining of VEGF by monocytes is observed in all cases (c: $\times 200$ ); Endothelial cells of vessel at tumor invasive edge or tumor stroma express VEGF (d: $x$ 200); Minute granules of VEGF are noted in esophageal squamous carcinoma cells (e: $\times 100$, f: $\times 200)$. 
cells, monocyte-macrophages, neutrophils, fibroblast-like cells, squamous carcinoma cells, and of endothelial cells themselves, in esophageal cancer tissue. Supra nuclear staining of VEGF was observed in esophageal glandular cells (Fig. 1b), but minute granular or diffuse staining was seen in monocytemacrophages (Fig. 1c), endothelial cells (Fig. 1d) and tumor cells (Fig. 1e, f). The tumor cells along with the endothelial cells of adjacent small blood vessels in the tumor stroma were stained strongly. In contrast, the normal distal squamous epithelium was stained very weakly or not at all (Fig. 1a), and the endothelial cells of small blood vessels in the normal distal epithelium were not stained. Smooth muscle cells of an artery or vein were sometimes weakly stained. VEGF expression by monocytemacrophages was observed in all cases and tended to be intensive at the tumor invasive edge. By contrast, the incidence of VEGF expression in the tumor cells $(1+$ or $2+)$ was observed in only $26.7 \%$ of

TABLE 1.

The expression of VEGF and tumor depth

\begin{tabular}{cccccc}
\hline \multirow{2}{*}{$\begin{array}{c}\text { VEGF } \\
\text { expression }\end{array}$} & \multicolumn{5}{c}{ Tumor depth } \\
\cline { 2 - 6 } & epm & sm & pT2 & pT3 & pT4 \\
\hline$(-)$ & 12 & 16 & 11 & 21 & 14 \\
$(+)$ & 1 & 8 & 4 & 10 & 4
\end{tabular}

Values are number of cases; VEGF $(+)$ includes $1+$ and $2+$ described in Materials and Methods; ep, mm, and sm mean superficial carcinoma. ep and $\mathrm{mm}$ are limited to mucosa. ep: carcinoma in situ, mm: tumor invades lamina muscularis mucosa, sm: tumor invades submucosa; pT2, pT3, and pT4 are defined according to TMN classification. cases (1+: $22.7 \%, 2+: 4.0 \%)$. However, in all cases where tumor cells were positive for VEGF, the tumor cells themselves were considered as the main source of the VEGF production.

Relationship between the expression of VEGF and pathological factors

As shown Table 1, the incidence of positive cases for VEGF in the tumor cells was low at $7.7 \%$ (1 of 13 ) in ep or mm cancer and was $33 \%$ (8 of 24 ) in sm cancer. There was no relationship between the expression of VEGF and histopathological factors such as lymph node involvement, histological tumor differentiation, lymphatic permeation or venous invasion (data not shown).

Correlation between vessel counts at the tumor invasive edge and VEGF expression

Among the 24 cases of sm cancer, 7 cases were associated with a small number of vessels ( $0-4)$, and 17 cases were associated with a large number of vessels (more than 5) at the tumor invasive edge. All the cases positive for VEGF in the tumor cells were associated with a large number of vessels. There

TABLE 2.

Relationship between the expression of VEGF and vessel counts at the tumor invasive edge (in the cases of sm cancer)

\begin{tabular}{ccc}
\hline VEGF & \multicolumn{2}{c}{ Vessel counts } \\
\cline { 2 - 3 } expression & $0-4$ & $5 \leqq$ \\
\hline$(-)$ & 7 & 9 \\
$(+)$ & 0 & 8 \\
\hline
\end{tabular}

Values are number of cases; VEGF $(+)$ includes $1+$ and $2+$ described in Materials and Methods, $\mathrm{p}<0.05(\times 2=4.941)$. 
was a significant correlation between the VEGF expression in the tumor cells and the vessel counts at the invasive edge (Table 2).

\section{Discussion}

We have determined the immunohistochemical localization of VEGF in esophageal squamous cell carcinoma tissues. VEGF was noted in tumor cells, normal esophageal glandular cells, inflammatory cells, fibroblasts and in endothelial cells of the blood vessels themselves. We found a statistically significant correlation between the expression of VEGF in the tumor cells and the density of vessels at the invasive edge. Recent studies (Takahashi et al. 1995; Warren et al. 1995) have demonstrated that KDR/Flk-1, as a receptor for VEGF, was expressed specifically in the endothelium of colon cancer tissues. These evidences suggested that VEGF might play a role in angiogenesis even in cancer tissue via either an autocrine and/or a para-crine mechanism. However, from our immunohistochemical study, the main cell source of VEGF production appeared to be the tumor cells, in all cases where the tumor cells were positive for VEGF. Also the expression of VEGF by stromal cells and normal esophageal glandular cells tended to be associated with the expression of this protein by tumor cells. In addition, Brown et al. (1993) demonstrated a higher expression of mRNA for VEGF using in situ hybridization in malignant colonic epithelium as compared to benign colon epithelial tumors.
Therefore, the existence of tumor cells may act as a trigger for VEGF-mediated angiogenesis in cancer tissues.

With regard to direct regulating factors of VEGF production, it has been reported that epidermal growth factor (EGF), basic fibroblast growth factor (bFGF) and/or platelet derived growth factor (PDGF) in human malignant glioma cell lines, and transforming growth factor- $\beta$ (TGF- $\beta$ ) in mouse embryo-derived cell line and human lung adenocarcinoma cell line induce VEGF production in vitro (Pertovaara et al. 1994; Tsai et al. 1995). VEGF mRNA expression is known to be stimulated by phorbol estel and cAMP analogus, indicating that both protein kinase $\mathrm{C}$ - and protein kinase Amediated pathways are involved in the regulation of VEGF gene expression (Claffey et al. 1992).

In cancer tissue, various stimulatory factors for VEGF are thought to be produced by the interaction of tumor cells and host cells. These factors are thought to be active in a wide range of tumor phenotypes resulting in the various concentration of VEGF expression in cancer tissue. Our studies have shown that there was no correlation with histopathological factors other than with tumor depth. Because the fms-like tyrosine kinase 1 (Flt-1) and the KDR/ Flk-1 receptor for VEGF have been shown to be expressed specifically in endothelial cells, we have to evaluate not only VEGF expression but also the receptors in cancer tissue to estimate true VEGF activity. Moreover, because several variant forms of VEGF generated by alternative mRNA splicing have different activities as a mitogen for 
endothelial cells or vascular permeability factor (DeVries et al. 1992; Terman et al. 1992; Millauer et al. 1993), it is important to evaluate individually the expression of the variant forms in cancer tissue. We expect that VEGF activity may have a strong correlation with tumor progression and metastatic spread, and become a useful clinical marker. VEGF may be a specific angiogenic factor which could potentially provide a target for anti-angiogenic therapy for cancer.

\section{References}

Bosari S, Lee AKC, Dlellis RA, Wiley BD, Heatley GJ et al. Microvessel quantitation and prognosis in invasive breast carcinoma. Hum Pathol 1992; 23:755-761.

Brown LF, Berse B, Jackman RW, Tognazzi K, Manseau EJ et al. Expression of vascular permeability factor (vascular endothelial growth factor) and its receptors in adenocarcinoma of the gastrointestinal tract. Cancer Res 1993; 53:4727-4735.

Claffey KP, Wilkison WO, and Spiegelman BM. Vascular endothelial growth factor. J Biol Chem 1992; 267:16313-16322.

Conn G, Bayne ML, Soderman DD, Kwok PW, Sullivan KA et al. Amino acid and cDNA sequences of a vascular endothelial cell mitogen that is homologous to plateletderived growth factor. Proc Natl Acad Sci U.S.A. 1990; 87:2628-2632.

DeVries C, Escobedo JA, Ueno H, Houck K, Ferrara $\mathrm{N}$ et al. The fms-like tyrosine kinese, a receptor for vascular endothelial growth factor. Science 1992; 255:989-991.

Ferrara N, Houck K, Jakeman L, and Leung DW. Molecular and biological properties of the vascular endothelial growth factor family of protein. Endocr Rev 1992; 13:18-32.

Folkman J. How is blood vessel growth regulated in normal and neoplastic tissue? G.
H. A. Clowes Memorial Award Lecture. Cancer Res 1986; 46:467-473.

Guidi AJ, Fischer L, Harris JR, and Schnitt SJ. Microvessel density and distribution in ductal carcinoma in situ of the breast. J Natl Cancer Inst 1994; 86:614-619.

Keck PJ, Hauser SD, Krivi G, Sanzo K, Warren T et al. Vascular permeability factor, an endothelial cell mitogen related to PDGF. Science 1989; 246:1309-1312.

Leung DW, Cachianes G, Kuang WJ, Goeddel DV, and Ferrara N. Vascular endothelial growth factor is a secreted angiogenic mitogen. Science (Washington DC) 1989; 246:1306.

Liotta L, Kleinerman J, and Saldel G. Quantitative relationships of intravascular tumor cells, tumor vessels, and pulmonary metastases following tumor implantation. Canver Res 1974; 34:997-1004.

Millauer B, Wizigmann-Voos S, Schnürch H, Martinez R, Møller NH et al. High affinity VEGF binding and developmental expression suggest Flk-1 as a major regulator of vasculogenesis and angiogenesis. Cell 1993; 72:835846.

Pertovaara L, Kaipainen A, Mustonen T, Orpana A, Ferrara $\mathrm{N}$ et al. Vascular endothelial growth factor is induced in response to transforming growth factor- $\beta$ in fibroblastic and epithelial cells. J Biol Chem 1994; 269:6271-6274.

Smith-McCune KK, and Weidner N. Demonstration and characterization of the angiogenic properties of cervical dysplasia. Cancer Res 1994; 54:800-804.

Takahashi Y, Kitadai Y, Bucana CD, Cleary KR, and Ellis LM. Expression of vascular endothelial growth factor and its receptor, $\mathrm{KDR}$, correlates with vascularity, metastasis, and proliferation of human colon cancer. Cancer Res 1995; 55:3964-3968.

Terman BI, Dougher-Vermazen M, Carrion EM, Dimitrov D, Armellino DC et al. Identification of the KDR tyrosine kinase as a receptor for vascular endothelial cell growth factor. Biochem Biophys Res Commun 1992; 187: 1579-1586. 
Tsai JC, Goldman CK, and Gillespie GY. Vascular endothelial growth factor in human glioma cell lines: induced secretion by EGF, PDGF-BB, and bFGF. J Neurosurg 1995; 82: 864-873.

Warren RS, Yuan H, Matli MR, Gillett NA, and Ferrara N. Regulation by vascular endothelial growth factor of human colon cancer tumorigenesis in a mouse model of experimental liver metastasis. J Clin Invest 1995; 95:1789-
1797.

Weidner N, Carroll PR, Flax J, Blumenfeld W, and Folkman J. Tumor angiogenesis correlates with metastasis in invasive prostate carcinoma. Am J Pathol 1993; 143:401-409.

Weidner N, Semple JP, Welch WR, and Folkman J. Tumor angiogenesis and metastasiscorrelation in invasive breast carcinoma. $\mathrm{N}$ Engl J Med 1991; 324:1-8. 